\title{
Cell-Free Bioassay for Measurement of Dioxins Based on Fluorescence Enhancement of Fluorescein Isothiocyanate-Labeled DNA Probe
}

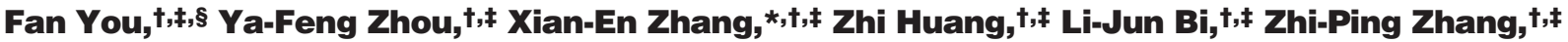 \\ Ji-Kai Wen,, ,‡ Yuan-Yuan Chen, ${ }^{,+\neq}$Gui-Bin Jiang," and Ming-Hui Zheng" \\ Joint Research Group on Analytical Pathogen Microbiology Wuhan Institute of Virology, Wuhan 430071, Chinese Academy \\ of Sciences and Institute of Biophysics, Beijing 100101, Chinese Academy of Sciences, State Key Laboratory of Virology \\ and State Key Laboratory of Virology and State Key Laboratory of Biomacromolecules, China, Graduate School, Chinese \\ Academy of Sciences, Beijing 100049, China, and Research Center for Eco-Environmental Sciences, Chinese Academy of \\ Sciences, Beijing 100085, China
}

This study aims to develop a rapid and sensitive cell-free bioassay of dioxins. It is known that dioxin ligand can bind heterodimeric aryl hydrocarbon receptor $(\mathrm{AhR})$ and triggers the formation of the complex of dioxin-AhR, AhR nuclear translocator (ARNT), and dioxin-responsive element (DRE) region of the DNA. The hypothesis of the proposed method is that if FITC were labeled at the DRE sequence, its fluorescence intensity would be enhanced when the complex forms because the interaction interface of the binding components (AhR, ARNT, and DRE) creates a rather hydrophobic condition that is in favor of FITC emission. Effects of modification site of FITC on the DNA probes on binding efficiency between the complex components and fluorescence emission enhancement were evaluated by surface plasmon resonance and fluorescence analysis, respectively. Results showed that the labeling site at the second base at the $5^{\prime}$ end apart from the core region (5'-TNGCGTG-3') of DRE did not obviously interfere with the binding between the DNA probe and dioxinAhR/ARNT hybrid but presented significant fluorescence emission enhancement. 2,3,7,8-Tetrachlorodibenzo-pdioxin (TCDD) was used as the typical toxin in this study. The method had a linear range of 1-100 pM, with detection limit of $0.1 \mathrm{pM}(0.64 \mathrm{fg} /$ assay $)$ and coefficient of variation of 5.6\% $(n=10,50 \mathrm{pM}$ TCDD in transformed cytosol). The whole detection cycle was $\sim 4 \mathrm{~h}$. The method was also used to estimate the toxic equivalents (TEQ) of 1,2,3,7,8-pentachlorodibenzo-p-dioxin (PeCDD) and 1,2,3,4,7,8-hexachlorodibenzo-p-dioxin (HxCDD). Measurement of TEQs of the mixture of TCDD, PeCDD, and HxCDD were highly consistent with the predicted data. The average recovery using fly ash extract was $\sim 93 \%$.

* Corresponding author. Tel: +86 10 58881508. Fax: +86 2787199492 E-mail: zhangxe@most.cn or zxecp@yahoo.com.cn.

$\dagger$ Joint Research Group on Analytical Pathogen Microbiology Wuhan Institute of Virology, Chinese Academy of Sciences and Institute of Biophysics, Chinese Academy of Sciences.

¥ State Key Laboratory of Virology and State Key Laboratory of Biomacromolecules.

$\$$ Graduate School.

"Research Center for Eco-Environmental Sciences.
Abbreviations: AHH, aryl hydrocarbon hydroxylase; AhR, aryl hydrocarbon receptor; Arnt, AhR nuclear translocator; CALUX, chemical-activated luciferase gene expression; DMSO, dimethyl sulfoxide; DRE, dioxin response element; ELISA, enzyme-linked immunosorbent assay; EPA, Environment Protection Agency; EROD, ethoxyresorufin-O-deethylase; FITC, fluorescein isothiocyanate; GRAB, gel retardation of AhR DNA binding; HRGC/MS, high-resolution gas chromatography/mass spectrometry; MDL, method detection limit; PCB, polychlorinated biphenyl; PCB28, 2,4,4'-polychlorinated biphenyls; PCB52, 2,2',5,5'-polychlorinated biphenyls; PCB101, 2,2',4,5,5'-polychlorinated biphenyls; PCB138, 2,2',3,4,4',5-polychlorinated biphenyls; PCB153, 2,2',4,4',5,5'-polychlorinated biphenyls; PCB180, 2,2',3,4,4',5,5'-polychlorinated biphenyls; PCDD, polychlorinated dibenzo-p-dioxins; RT, room temperature; RU, resonance unit; SPR, surface plasmon resonance; TCDD, 2,3,7,8-tetrachlorodibenzo-p-dioxin; TEF, dioxin toxic equivalents factor; TEQ, toxic equivalents.

Polychlorinated dibenzo-p-dioxins (PCDDs) and polychlorinated biphenyls (PCBs) are well-known groups of highly toxic and widespread environmental pollutants. PCDDs have 75 positional congeners with wide differences in toxicity. ${ }^{1,2}$ In particular, 2,3,7,8-tetrachlorodibenzo-p-dioxin (TCDD) is known as the most toxic congener. These compounds have been extensively studied and are known to accumulate in animals causing toxic effects, such as birth defects, immunotoxicity, tumor production, changes in metabolism, and even death as a result of exposure to them..$^{3-5}$ Therefore, detection of these compounds is of critical importance.

So far, combination of high-resolution gas chromatography and high-resolution mass spectrometry (HRGC/MS) is regarded as the golden standard for sufficient sensitivity (parts per trillion) and selectivity for determination of PCDDs including TCDD. ${ }^{6}$ However, the technique is very skillful and time-consuming; it requires specialized equipment and a dedicated laboratory.

(1) Rappe, C. Environ. Sci. Technol. 1984, 18, 78A-90A.

(2) WHO. Fact sheet No. 225, June 1999.

(3) Whysner, J.; Williams, G. M. Pharmacol. Ther. 1996, 71, 193-223.

(4) Poland, A.; Knutson, J. C. Annu. Rev. Pharmacol. Toxicol. 1982, 22, 517554.

(5) Kimbrough, R. D.; Falk, H.; Stehr, P.; Fries, G. J. Toxicol. Environ. Health 1984, 14, 47-93.

(6) USEPA, 1994.

10.1021/ac060442e CCC: $\$ 33.50$ (c) 2006 American Chemical Society Published on Web 09/01/2006 
Depending on the amount of sample preparation, the analysis usually takes several days to complete. And although HRGC/MS provides an accurate measurement of each of the known isomers and congeners in sample extracts, it is not reliable for predicting the toxicity of complex mixtures of congeners. Thus, more rapid and cost-effective methods are in demand for screening of large numbers of samples.

In vitro bioassays based on the ligand-target binding reaction are good alternatives.TCDD and structurally related compounds can induce a wide range of biological responses through the aryl hydrocarbon receptor (AhR) signal transduction pathway.,8 The AhR is a ligand-activated and dependent transcription factor that mediates many of the biological and toxicological effects of dioxinrelated compounds. ${ }^{9,10}$ After the binding of ligands, the AhR subsequently transforms into a high-affinity DNA binding form, translocates into the nucleus, and then forms a heterodimer with AhR nuclear translocator (ARNT). ${ }^{11-13}$ The complex of ligandAhR-ARNT interacts with a specific DNA sequence (5'-TNGCGTG$3^{\prime}$ ), the dioxin-responsive element (DRE), resulting in transcriptional activation of adjacent genes. ${ }^{11,14,15}$ Bioassays based on AhR mechanism not only are rapid and cost-effective but also could provide biologic potency information of either individual congeners or complex mixtures. Some have been approved by the governmental authorities in the United States, such as Environment Protection Agency (EPA) method 4425 (reporter gene assay) and EPA method 4025 (immunoassay). ${ }^{16-18}$

Several in vitro bioanalytical methods have been developed to analyze Ah receptor agonists in a cost-and-time effective way such as the aryl hydrocarbon hydroxylase (AHH)/ethoxyresorufin-Odeethylase (EROD) bioassay ${ }^{19,20}$ and chemical-activated luciferase gene expression (CALUX) bioassay. ${ }^{21-23}$ The AHH/EROD bioassay measures AhR-mediated cytochrome P-450 1A1 induction,

(7) Brouwer, A.; Ahlborg, U. G.; Van den Berg, M.; Birnbaum, L. S.; Boersma E. R.; Bosveld, B.; Denison, M. S.; Gray, L. E.; Hagmar, L.; Holene, E.; et al. Eur. J. Pharmacol. 1995, 293, 1-40.

(8) Denison, M. S.; Phelan, D.; Elferink, C. J. Xenobiotics, Receptors and Gene Expression; Taylor and Francis; Philadelphia, 1998; pp 3-33.

(9) Safe, S. Crit. Rev. Toxicol. 1990, 21, 51-88.

(10) Garrison, P. M.; Tullis, K.; Aarts, J. M.; Brouwer, A.; Giesy, J. P.; Denison, M. S. Fundam. Appl. Toxicol. 1996, 30, 194-203.

(11) Whitlock, J. P., Jr. Chem. Res. Toxicol. 1993, 6, 754-763.

(12) Probst, M. R.; Reisz-Porszasz, S.; Agbunag, R. V.; Ong, M. S.; Hankinson, O. Mol. Pharmacol. 1993, 44, 511-518.

(13) Hankinson, O. Annu. Rev. Pharmacol. Toxicol. 1995, 35, 307-340.

(14) Denison, M. S.; Fisher, J. M.; Whitlock, J. P., Jr. J. Biol. Chem. 1988, 263, 17221-17224.

(15) Denison, M. S.; Pandini, A.; Nagy, S. R.; Baldwin, E. P.; Bonati, L. Chem.Biol. Interact. 2002, 141, 3-24.

(16) Cooke, M.; Clark, G. C.; Goeyens, L.; Baeyens, W. In Today's Chemist at Work. American Chemical Society: Washington, DC, 2000; Vol. 9, pp 3439.

(17) USEPA Method 4425: Screening extracts of environmental samples for planar organic compounds (PAHS, PCBS, PCDDS/PCDFS) by a reporter gene on a human cell line. EPA Office of Solid Waste, SW846 Methods, Update IVB; November 2000.

(18) USEPA Method 4025: Screening for PCDD/PCDF by Immunoassay (In Submission as a New 4000 Series Method); October 2002.

(19) .(19)Bradlaw, J. A.; Casterline, J. L., Jr. J. Anal. Chem. 1979, 62, 904-916.

(20) Bradlaw, J. A.; Garthoff, L. H.; Hurley, N. E.; Firestone, D. Food Chem. Toxicol. 1980, 18, 627-635.

(21) Denison, M. A.; El-Fouly, M. H.; Aarts, J.; Brouwer, A.; Richter, C.; Giesy, J. P. Organohalogen Compd. 1993, 13, 365-368.

(22) Postlind, H.; Vu, T. P.; Tukey, R. H.; Quattrochi, L. C. Toxicol. Appl. Pharmacol. 1993, 118, 255-262.

(23) Murk, A. J.; Legler, J.; Denison, M. S.; Giesy, J. P.; van de Guchte, C.; Brouwer, A. Fundam. Appl. Toxicol. 1996, 33, 149-160. and the CALUX bioassay measures the production of the luminescent enzyme luciferase after a luciferase reporter with DRE responsive to the liganded AhR complex. These bioassays utilize mammalian cell culture to measure a specific response to detect the sum of dioxin-like activity. Thus cell culture is necessary. The detection limit for EROD induction by TCDD in HEIIE cells is about 58 190 fg TCDD/well and the linear working range is $10 \sim 1000 \mathrm{pg} /$ assay. ${ }^{24-27}$ It usually takes $24 \sim 72 \mathrm{~h}$ to run the test. The current method detection limit (MDL) of the CALUX bioassay is between 43 and $640 \mathrm{fg} /$ well or tube. It takes $4-48 \mathrm{~h}$ to perform the whole procedure. ${ }^{10,22,28,29}$

There are also some non-cell-based bioanalytical detection methods including the gel retardation of AhR DNA bonding (GRAB) assay (measurement of the inducible AhR binding to ${ }^{32}$ P-labeled DRE), ${ }^{30}$ immunoassay (using polyclonal antibodies or Mab for dioxins by ELISA), ${ }^{31,32}$ surface plasmon resonance (SPR) sensor, ${ }^{33,34}$ immunoaffinity chromatography, ${ }^{35,36}$ and anti-Arnt antibody by binding to the transformed AhR, ${ }^{37}$ The AhR binding assay is the measurement of relative binding affinities to the AhR by dioxin-like compounds using competitive ligand binding with radiolabeled dioxin ligands. ${ }^{9,38}$ The above assays are based on the ability of key biological molecules (e.g., polyclonal antibodies, monoclonal antibodies, isotopes) to recognize a unique structural property of the dioxin-like compounds, which are hard obtain for many researchers. Introduction of polymerase chain reaction (PCR) substantially increased detection sensitivity. The methods EMP-PCR and AhRC-PCR could have detection limits as low as $10-15 \mathrm{pM} .{ }^{39,40}$

Fluorescein isothiocyanate (FITC) is one of the most commonly used fluorescent dyes. Its fluorescence intensity would enhance apparently when the surrounding environment of FITC becomes hydrophobic. ${ }^{41}$ Since the phase transit may happen in

(24) Sanderson, J. T.; Aarts, J. M.; Brouwer, A.; Froese, K. L.; Denison, M. S.; Giesy, J. P. Toxicol. Appl. Pharmacol. 1996, 137, 316-325.

(25) Schwirzer, S. M.; Hofmaier, A. M.; Kettrup, A.; Nerdinger, P. E.; Schramm, K. W.; Thoma, H.; Wegenke, M.; Wiebel, F. J. Ecotoxicol. Environ. Saf. 1998 41, 77-82.

(26) Tillitt, D. E.; Ankley, G. T.; Verbrugge, D. A.; Giesy, J. P.; Ludwig, J. P.; Kubiak, T. J. Arch. Environ. Contam. Toxicol. 1991, 21, 91-101.

(27) Tillitt, D. E.; Giesy, J. P.; Ankley, G. T. Environ. Sci. Technol. 1991, 25, 87-92.

(28) Bovee, T. F.; Hoogenboom, L. A.; Hamers, A. R.; Traag, W. A.; Zuidema, T.; Aarts, J. M.; Brouwer, A.; Kuiper, H. A. Food Addit. Contam. 1998, 15, 863-875.

(29) Ziccardi, M. H.; Gardner, I. A.; Denison, M. S. Toxicol. Sci. 2000, 54, 183193.

(30) Seidel, S. D.; Li, V.; Winter, G. M.; Rogers, W. J.; Martinez, E. I.; Denison, M. S. Toxicol. Sci. 2000, 55, 107-115

(31) Albro, P. W.; Luster, M. I.; Chae, K.; Chaudhary, S. K.; Clark, G.; Lawson, L. D.; Corbett, J. T.; McKinney, J. D. Toxicol. Appl. Pharmacol. 1979, 50, 137-146.

(32) Stanker, L. H.; Watkins, B.; Rogers, N.; Vanderlaan, M. Toxicology 1987, 45, 229-243.

(33) Shimomura, M.; Nomura, Y.; Zhang, W.; Sakino, M.; Lee, K. H.; Ikebukuro, K.; Karube, I. Anal. Chim. Acta 2001, 434, 223-230.

(34) Soh, N.; Tokuda, T.; Watanabe, T.; Mishima, K.; Imato, T.; Masadome, T.; Asano, Y.; Okutani, S.; Niwa, O.; Brown, S. Talanta 2003, 60, 733-745

(35) Shelver, W. L.; Huwe, J. K. J. Liq. Chromatogr. Relat. Technol. 1999, 22, $813-821$.

(36) Huwe, J. K.; Shelver, W. L.; Stanker, L.; Patterson, J. D. G.; Turner, W. E. J. Chromatogr., B: Biomed. Sci. Appl. 2001, 757, 285-293.

(37) Wheelock, G. D.; Hurst, K. R.; Babish, J. G. Toxicol. Mech. Methods 1996 , $6,41-50$.

(38) Bunce, N. L. Organohalogen Compd. 1995, 23, 209-213.

(39) Sun, X.; Li, F.; Wang, Y. J.; Li, Y. R.; Su, Y. H.; Li, Y. Y.; Yan, H.; Xu, S. Q. Toxicol. Sci. 2004, 80, 49-53.

(40) Allen, R. L. Organohalogen Compd. 2002, 58, 341-343. 


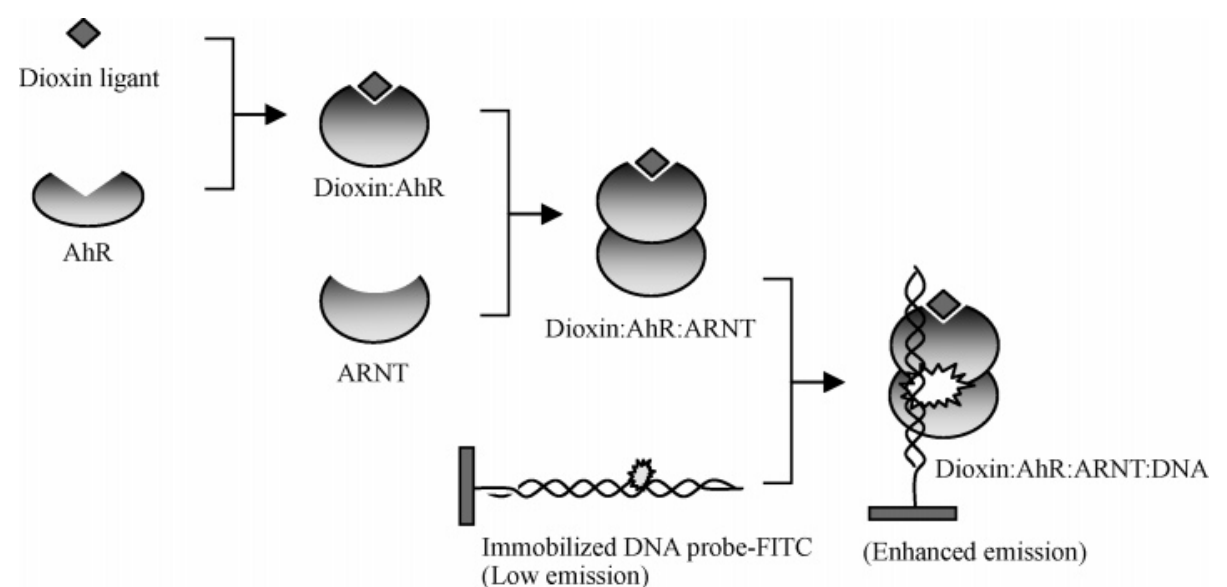

Figure 1. Principle of fluorescence enhancement of DNA probe assay.

many molecular binding reactions, the principle has been exploited for sensitive measurement of ligand-receptor bindings, ${ }^{42}$ proteinprotein interactions,,${ }^{43,44}$ enzyme - substrate reactions, ${ }^{45}$ etc.

Here, we proposed a new cell-free bioassay based on the AhRdependent mechanism and fluorescence enhancement principle. As shown in Figure 1, it is proposed that when the dioxin ligand binds AhR and triggers the formation of the complex dioxinAhR-ARNT-DNA-FITC, a hydrophobic phase would be created at the molecular interaction interface, which is in favor of FITC emission. The binding is thus traced by monitoring the enhanced fluorescence. These molecular interactions may provide a cellfree bioassay system for sensitive detection of dioxins and might serve as a new measure for evaluation of toxicity and potency value of dioxins. The results of the experiment are presented herein.

\section{MATERIALS AND METHODS}

Chemicals, Reagents, and Oligonucleotide Probes. TCDD, dimethyl sulfoxide (DMSO), and polychlorinated biphenyls, including 2,4,4'-polychlorinated biphenyls (PCB28), 2,2',5,5'-polychlorinated biphenyls (PCB52), 2,2',4,5,5'-polychlorinated biphenyls (PCB101), 2,2',3,4,4',5-polychlorinated biphenyls (PCB138),

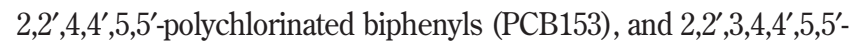
polychlorinated biphenyls (PCB180), were purchased from Supleco and Sigma (St. Louis, MO). 1,2,3,7,8-Pentachlorodibenzo-p-dioxin (PeCDD), 1,2,3,4,7,8-hexachlorodibenzo-p-dioxin (HxCDD), 1,2,3,4,6,7,8,9-octachlorodibenzo-p-dioxin (OCDD), and fly ash extract (Laboratory Sample p0301011, National Research Center for Environment and Health, Germany) were kindly donated by Prof. Gui-bin Jiang and Prof. Ming-Hui Zheng.

Detection of the transformed AhR was performed with 21-bp double-stranded oligonucleotide probes containing a DRE region as listed in Table 1 . The probes were formed by annealing corresponding oligonucleotides, which were synthesized at Takara Bio Inc. (Shiga, Japan).

(41) Hiratsuka, T. Biochim. Biophys. Acta 1976, 453, 293-297.

(42) Johnson, D. A.; Brown, R. D.; Herz, J. M.; Berman, H. A.; Andreasen, G. L.; Taylor, P. J. Biol. Chem. 1987, 262, 14022-14029.

(43) Aoyagi, S.; Miyasaka, T.; Yoshimi, Y.; Sakai, K. Artif. Organs 2002, 5, 6063.

(44) Aoyagi, S.; Imai, R.; Sakai, K.; Kudo, M. Biosens. Bioelectron. 2003, 18, 791-795.

(45) Yang, S. J.; Jiang, S. S.; Van, R. C.; Hsiao, Y. Y.; Pan, R. Biochim. Biophys. Acta 2000, 1460, 375-383.

\section{Table 1. Oligonucleotides Sequences for Probes I and II and WT}

\begin{tabular}{cc} 
probe & \multicolumn{1}{c}{ sequence $^{a}$} \\
I & biotin-5'-TTTTTTTTTTGGCTCTTCTCACGCAACTCCG-3' \\
II & 3'-CCGAGAAGAGTGCGTTGAGGC-5' \\
biotin-5'-TTTTTTTTTTGGCTCTTCTCACGCAACTCCG-3' \\
WT & $\begin{array}{l}\text { 3'-CCGAGAAGAGTGCGTTGAGGC-5' } \\
\text { biotin-5'-TTTTTTTTTGGCTCTTCTCACGCAACTCCG-3' } \\
\text { 3'-CCGAGAAGAGTGCGTTGAGGC-5' }\end{array}$
\end{tabular}

${ }^{a}$ The boldface type indicates the recognition and binding site of the dioxin-AhR-ARNT complex, DRE, and the underlined indicates the FITC labeling site.

Preparation of Rat Hepatic Cytosol. Rat hepatic cytosol was used as a source of AhR complex to determine the transformation in a cell-free system. Male Sprague-Dawley (SD) rats (140-170 $\mathrm{g}$ ), allowed food and water, were exposed to $12 \mathrm{~h}$ of light and 12 $\mathrm{h}$ of dark daily. Livers from SD rats were perfused with ice-cold phosphate-buffered saline and homogenized in a double volume of HEDG buffer (25 mM HEPES pH7.4, $1.5 \mathrm{mM}$ EDTA, $1.0 \mathrm{mM}$ dithiothreitol, $10 \%$ glycerol). The homogenate was centrifuged at $105000 \mathrm{~g}$ for $70 \mathrm{~min}$, and the supernatant was used as cytosol..$^{46}$ The cytosol was divided into portions and stored at $-80^{\circ} \mathrm{C}$ until use.

Transformation of AhR. Protein concentrations of cytosol were measured by the BCA protein assay reagent (Pierce) and diluted to $10-15 \mathrm{mg} / \mathrm{mL}$ diluted in HEDG buffer. The cytosol was incubated with dioxin or dioxin-like compounds at various concentration at $16-20{ }^{\circ} \mathrm{C}$ for $2 \mathrm{~h}$ in the dark, yielding the transformed cytosol. DMSO was incubated in the same condition as a control.

Immobilization of Fluorescence-Labeled DRE Probe on the SA-Chip Surface. SA-chip, for coupling biotinylated probes, was used to identify the binding of transformed AhR to the probles using BIAcore 3000 (BIAcore AB, Uppsala, Sweden). The chip surface was first cleaned with three consecutive 1-min injections of $40 \mu \mathrm{L}$ of $1 \mathrm{M} \mathrm{NaCl}$ in $50 \mathrm{mM} \mathrm{NaOH}$ before the immobilization procedure. When the sensorgram reached a stable baseline, the biotinylated probe, diluted in running buffer (10 mM HEPES, 10

(46) Denison, M. S.; Vella, L. M.; Okey, A. B. J. Biol. Chem. 1986, 261, 39873995.

7140 Analytical Chemistry, Vol. 78, No. 20, October 15, 2006 

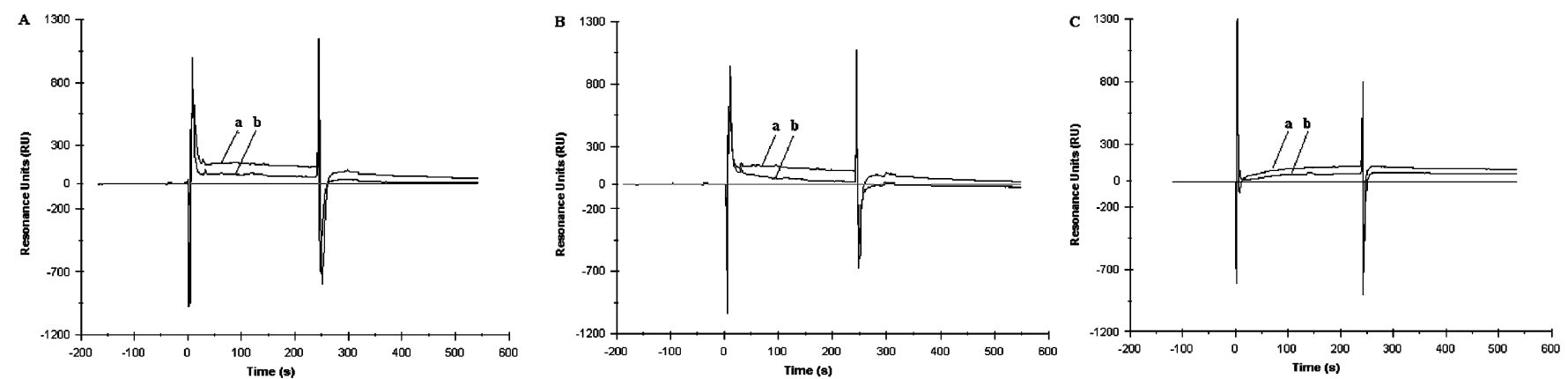

Figure 2. SPR measurement of the interaction between the TCDD-incubated cytosol and immobilized DRE probes. (A) probe I, (B) probe II, and (C) probe WT. The cytosol samples were previously incubated with (a) 0.6 or (b) 0.06 pM TCDD. The sensorgrams were obtained by subtracting the DMSO signals from those of the sample.

$\mathrm{mM} \mathrm{MgCl}_{2}, 150 \mathrm{mM} \mathrm{NaCl}, \mathrm{pH}$ 7.4) to $5 \mu \mathrm{M}$, was injected for 1 min using a flow rate of $5 \mu \mathrm{L} / \mathrm{min}$. Loosely attached material was removed by three cycles of $10 \mu \mathrm{L}$ of $10 \mathrm{mM} \mathrm{NaOH}$.

Probe Identification by SPR. All buffers for SPR experiments were filtered (pore size $0.22 \mu \mathrm{m}$ ) and degassed before use. The concentration of cytosol was diluted to $2-3 \mathrm{mg} / \mathrm{mL}$ in HEDK buffer (25 mM HEPES, $1.5 \mathrm{mM}$ EDTA, $1.0 \mathrm{mM}$ dithiothreitol, $180 \mathrm{mM} \mathrm{KCl}, \mathrm{pH} 7.4$ ). The adjusted cytosol was incubated with dioxin at various concentrations, and the resulting mixtures were injected over the DNA-specific surface at $5 \mu \mathrm{L} / \mathrm{min}$ for $4 \mathrm{~min}$. The chip surface was regenerated by injection of $10 \mu \mathrm{L}$ of $50 \mathrm{mM}$ $\mathrm{NaOH}$ for $1 \mathrm{~min}$. Sensor surface without DNA coating was used as the reference surface. All experiments were performed at 25 ${ }^{\circ} \mathrm{C}$ within the same flow cell.

Immobilization of Fluorescence-Labeled DRE Probes on Plate. Probes I and II were diluted in PBS buffer $(100 \mathrm{mM}$ sodium phosphate, $150 \mathrm{mM} \mathrm{NaCl}, \mathrm{pH} 7.2$ ) at appropriate concentrations and then $20 \mu \mathrm{L}$ was added to each well of the streptavidin-coated black 384-well plates (No. 15506, Pierce Biotechnology Inc.). The plate was incubated at room temperature for $60 \mathrm{~min}$. After each well was rinsed with $3 \times 100 \mu \mathrm{L}$ of PBS, the plate was blocked with $2 \%$ PBSM (skimmed milk) for $60 \mathrm{~min}$ at room temperature and washed three times with PBS.

Fluorescence Enhancement Assay. The reaction mixture, containing $2 \mu \mathrm{L}$ of transformed cytosol and $18 \mu \mathrm{L}$ of HEDK buffer, was plated into DRE probe-bound well of the plate and incubated for $2 \mathrm{~h}$ at room temperature in the dark. The samples were then excited at $485 \mathrm{~nm}$ and fluorescence emissions were monitored at $528 \mathrm{~nm}$ with a total band-pass of $20 \mathrm{~nm}$ by the Microplate Reader (Bio-Tek Instruments Inc.). Data obtained were ananlyzed using the computer program KC4 v3.0 with PowerReports.

Safety Consideration. When dioxins and related compounds are handled, two pairs of protective gloves are worn with some water between the two layers to avoid penetration of highly lipophilic compounds through the gloves. UV light has been reported to degrade dioxins and some related compounds and thus may be useful for cleanup operations. ${ }^{47,48}$

\section{RESULTS AND DISCUSSION}

SPR Analysis. To evaluate the binding activity of the designed DRE probes to the heterodimer with TCDD, we measured the

(47) Crosby, D. G.; Wong, A. S.; Plimmer, J. R.; Woolson, E. A. Science 1971, 173, 748-749.

(48) Qin, Z. Chemosphere 1996, 33, 91-97.

\begin{tabular}{lccc}
\hline \multicolumn{4}{l}{ Table 2. Relative Response Units } \\
& $\begin{array}{c}c \\
\text { increased RU }\end{array}$ & \multicolumn{2}{c}{ response, RU } \\
\cline { 2 - 3 } probe & $\begin{array}{l}\text { after immobil } \\
\text { TCDD }(0.6 \mathrm{pM})\end{array}$ & TCDD $(0.06 \mathrm{pM})$ \\
I & 340 & $66.9 \pm 16.0$ & $21.2 \pm 7.4$ \\
II & 353 & $32.6 \pm 14.1$ & $1.5 \pm 0.5$ \\
WT & 364 & $87.9 \pm 18.8$ & $45.2 \pm 18.1$ \\
\hline
\end{tabular}

interaction between probes I, II, and wild types (WTs), and the transformed cytosol by biomolecular interaction analysis in real time using BIAcore 3000, with probe WT as a wild-type control, which had no FITC labeling site. DMSO, the solvent blank, gave a shift of less than 15 resonance units (RUs), which was used as the baseline. The baseline subtracted from the response signals gives the sensorgrams shown in Figure 2, where A, B, and C present the response signals of the sensor chips modified with probes I, II, and WT to the cytosol containing 0.6 and $0.06 \mathrm{pM}$ TCDD, respectively. The curves clearly show that all probes can bind the heterodimer with TCDD. But when the concentration of TCDD was $0.06 \mathrm{pM}$, curve $\mathrm{b}$ in Figure $2 \mathrm{~B}$ was nearly undetectable from the zero curve in the dissociation phase. Binding was quantified as an increase in RU (showed in Table 2) at $72 \mathrm{~s}$ after the end of injection compared to a baseline at $20 \mathrm{~s}$ prior to injection. The data were presented as mean \pm standard deviation (SD) by at least three independent experiments. The values in Table 2 showed that the binding affinity of the complex dioxinAhR-ARNT-DNA-FITC for probe I was slightly higher than that for probe II, indicating that probe I was probably the better candidate. Large spikes at the beginning and the end of the injections were recorded, which might be caused by sample/buffer switching between the flow channels and, possibly, the effect of complex proteins in the cytosol on refractive index.

Fluorescence Analysis. The fluorescence enhancement by the bonding of complex to the FITC-labeled probes was proved by fluorescence analysis. Figure 3 shows the fluorescence emission spectrum with 480-nm excitation. The fluorescence intensities of the transformed cytosol with 3.25 and $32.5 \mathrm{pM}$ TCDD were significantly higher than that of the cytosol with DMSO. This phenomenon was a direct indication that binding of the AhR complex to the FITC-labeled probes had created a rather hydrophobic microenvironment that favored the emission of FITC. Probe I produced stronger fluorescence enhancement than probe II. In combination with the SPR results, probe I was more suitable 

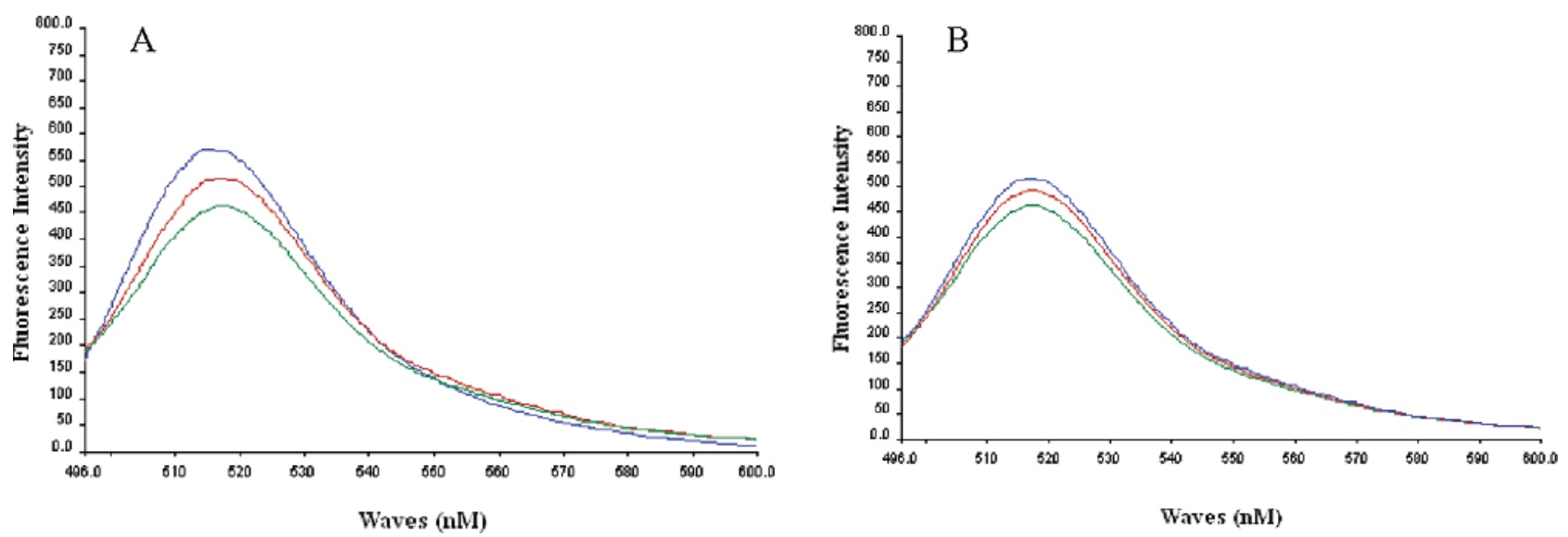

Figure 3. Fluorescence analysis of DRE probes. (A) Probe I; (B) probe II. (Top to bottom: (a) TCDD 32.5 pM; (b) TCDD 3.25 pM; (c) DMSO. Excitation, $480 \mathrm{~nm} ; 5 \mathrm{~nm}$ of slit width for both excitation and emission light. Probes I and II were added to $40 \mu \mathrm{L}$ of transformed cytosol at a concentration of $10 \mathrm{nM}$. The final volume of the reaction was $500 \mu \mathrm{L}$ in HEDK buffer, incubation was at room temperature for 60 min, and then detection by PE LS55 (PerkinElmer Life And Analytical Sciences Inc.).

for the proposed purpose and thus was used in the following experiments.

Solvent Effect and Sample Detection Calculation. As DMSO is recommended as the solvent of dioxins, its solvent effect on fluorescence measurement was investigated. The shift of the fluorescence intensity was less than $2.5 \%$ when the concentration of DMSO was in the range of $0.1 \mathrm{pM}-10 \mathrm{nM}$. Therefore, the detection limit was defined as the concentration of TCDD at which the relative enhanced fluorescence intensity was $5 \%$, i.e., 2 -fold that of the DMSO signal. The enhanced fluorescence by TCDD was defined as follows,

$$
F_{\mathrm{EN}}=\left(F_{\mathrm{TCDD}}-F_{\mathrm{DMSO}}\right) / F_{\mathrm{DMSO}}
$$

Here, $F_{\mathrm{EN}}$ is the relative enhanced fluorescence intensity, $F_{\mathrm{TCDD}}$ is the measured total fluorescent intensity, and $F_{\mathrm{DMSO}}$ is the background fluorescent intensity of the control that contained DMSO with concentration identical to the solvent of the TCDD sample solution.

Fluorescence Enhancement of Probe I by TCDD. Considering the efficiency of immobilization of the DNA probe and an appropriate ratio of probe to the ligand-AhR complex, the fluorescence enhancement assays were performed with different concentrations of DNA probe. As shown in Figure 4, the value of the fluorescence enhancement increased with an increase of TCDD, and the response linear ranges varied with variation of DNA probe concentration. The detection specifications using probe I at different concentrations are summarized in Table 3 . As can be seen, the substrates TCDD induced notable increases of fluorescence intensity at all concentrations of the immobilized probe I. A slight loss in specific binding at a high ligand concentration emerged maybe because of the "hook effect". The fluorescence enhancement of $500 \mathrm{pM}$ probe I achieved a response linear range of 1-100 pM with detection limit of $0.1 \mathrm{pM}(0.64$ fg/assay) and a maximum response of $\sim 50 \%$ (Figure $4 \mathrm{C}$ ). Increasing the concentration of probe I to $50 \mathrm{nM}$ could enlarge the response linear range, but produced no increase of fluorescence enhancement, which probably means too densely im- mobilized probes could not afford enough space to the AhR complex. Therefore, a concentration of $500 \mathrm{pM}$ probe I was selected to prepare the detection plates throughout the following experiments. To further estimate the reproducibility of the method, a transformed cytosol containing 50 pM TCDD was tested 10 times. The mean of relative fluorescence enhancement was 29.1 and SD was 1.62 (Table 4), which gives a coefficient of variation $(\mathrm{CV})$ of $5.6 \%(\mathrm{CV}=$ standard deviation/mean $\times 100 \%)$.

Analysis of HAHs and PAHs. To assess the effects of other AhR ligands, three dioxin congeners, including 1,2,3,7,8-PeCDD, 1,2,3,4,7,8-HxCDD, and OCDD, were tested by probe I with a concentration of $500 \mathrm{pM}$ for immobilization. Fluorescence enhancements induced by AhR transformation treated with each compound were carried out, and the results are shown in Figure 5 . The linear detection ranges were $10 \mathrm{pM}-1 \mathrm{nM}$ and 100 $\mathrm{pM}-10 \mathrm{nM}$ for 1,2,3,7,8-PeCDD and 1,2,3,4,7,8-HxCDD, respectively. There was almost no increased fluorescence intensity observed for OCDD.

Structure-activity relationships for TCDD and related compounds (AhR agonists) have been extensively investigated, and for most responses, there were rank order correlations between their AhR binding affinities and AhR-mediated toxic and biochemical responses. The toxic equivalency factor (TEF) has been extensively used to investigate the biochemical and toxic effects and mechanism of action of dioxins. ${ }^{11,51}$ In this study, the most toxic congener, TCDD, was assigned a TEF of 1.0. TEFs of 1,2,3,7,8-PeCDD and 1,2,3,4,7,8-HxCDD are 0.49, and 0.16, respectively, using the proposed method, which are in the range of the literature data for PCDDs. ${ }^{9}$ The mixtures of these compounds with different concentrations were detected and the results showed that the determined toxic equivalencies were consistent with the calculated data (Table 5).

Six PAHs, including PCB28, PCB52, PCB101, PCB138, PCB153, and PCB180, were tested as well. No obvious increase of fluorescence intensity was observed, though PCB52 or PCB153

(49) Swanson, H. I.; Chan, W. K.; Bradfield, C. A. J. Biol. Chem. 1995, 270 26292-26302.

(50) Yao, E. F.; Denison, M. S. Biochemistry 1992, 31, 5060-5067.

(51) Safe, S. H. Pharmacol. Ther. 1995, 67, 247-281. 

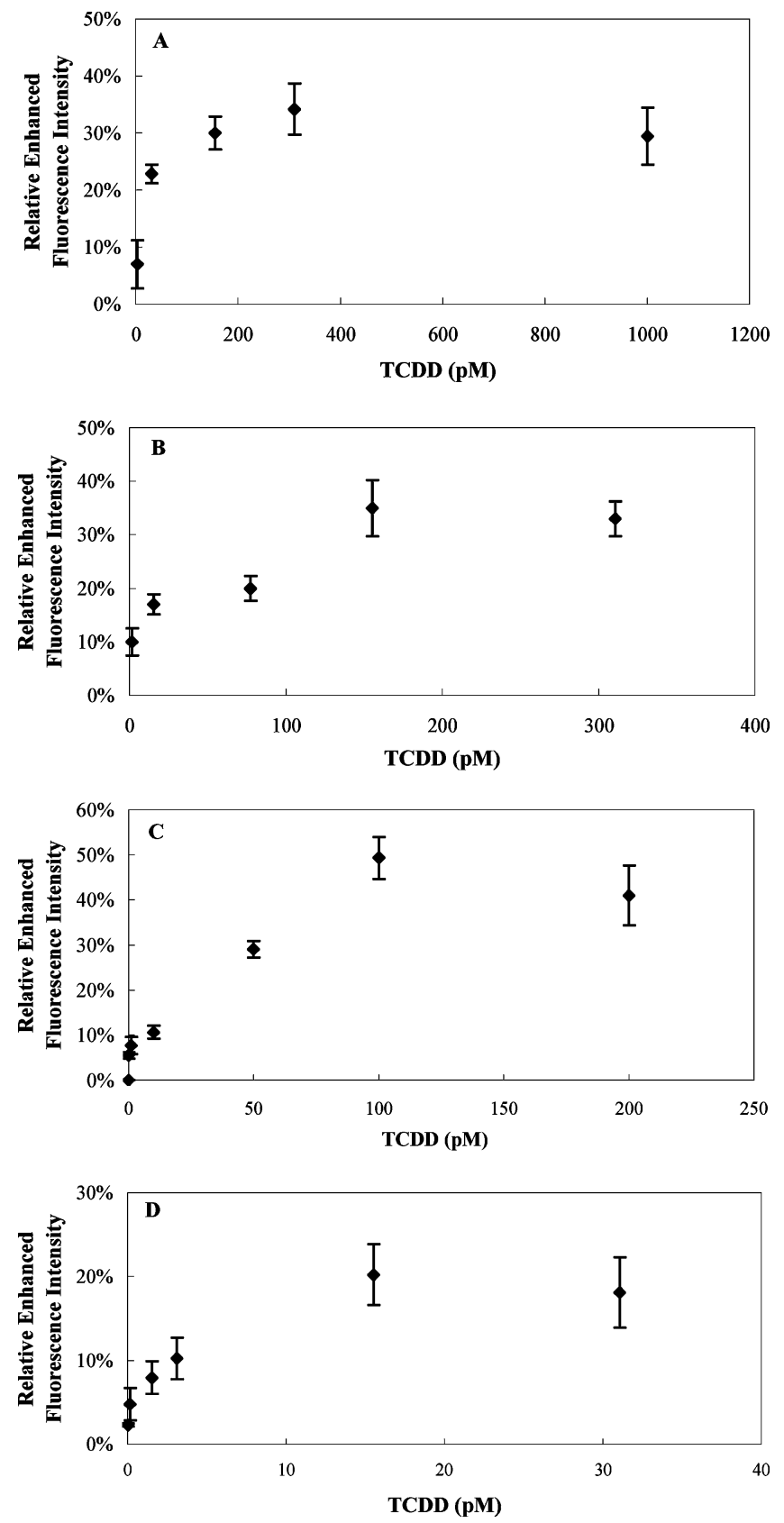

Figure 4. Relationship between relative enhanced fluorescence intensity, TCDD concentration, and concentration of the immobilized probe I. The concentrations of the immobilized probe I were $50 \mathrm{nM}$ (A), $5 \mathrm{nM}(\mathrm{B}), 500 \mathrm{pM}(\mathrm{C})$, and $50 \mathrm{pM}(\mathrm{D})$. All data were the averages of three independent experiments, each with triplicates. Error bars are presented as mean $\pm \mathrm{SD}$.

had a response of fluorescence enhancement at $\sim 5 \%$ when the concentration reached $30 \mathrm{nM}$, which was the highest concentration in these experiments. The ortho-substituted nonplanar PCBs (PCB-22, -52, -101, -138, -153, and -180) are phenobarbital-like PCBs. Structure-toxicity studies suggest that the coplanar PCBs are AhR-dependent. The nonplanar PCBs are AhR-independent and relatively low in toxicity without TEF values. ${ }^{52,53}$ Our results are in accordance with the facts.

Analysis of Fly Ash Extract and Recovery Test. Fly ash extract, a standard sample for dioxin analysis in laboratories, was

(52) Brouwer, A.; van den Berg, K. J. Toxicol. Appl. Pharmacol. 1986, 85, 301312.
Table 3. Detection Specification Using Probe I at Different Concentrations

max re

concn of detection linear range, sensitivity/ fluorescence

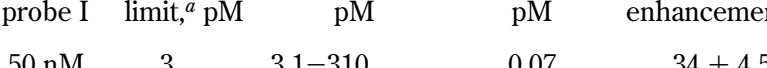

$\begin{array}{lllll}50 \mathrm{nM} & 3 & \begin{array}{c}3.1-310 \\ \left(R^{2}=0.72\right)\end{array} & 0.07 & 34 \pm 4.5 \\ 5 \mathrm{nM} & 1.55 & \begin{array}{c}1.5-150 \\ \left(R^{2}=0.93\right)\end{array} & 0.15 & 35 \pm 5.2 \\ 500 \mathrm{pM} & 0.1 & \begin{array}{c}1-100 \\ \left(R^{2}=0.98\right)\end{array} & 0.45 & 50 \pm 4.7 \\ 50 \mathrm{pM} & 0.03 & \begin{array}{c}0.5-50 \\ \left(R^{2}=0.93\right)\end{array} & 1.02 & 20 \pm 3.6\end{array}$

${ }^{a}$ Detection limit was defined as the concentration of TCDD at which the relative enhanced fluorescence intensity was twice the background signal.

\section{Table 4. Reproducibility of the Assay Using Probe $I^{a}$}

rel fluorescence enhancement, \%

$$
\text { mean }
$$

SD

$\mathrm{CV}$
${ }^{a}$ The transformed cytosol contained $50 \mathrm{pM}$ TCDD.

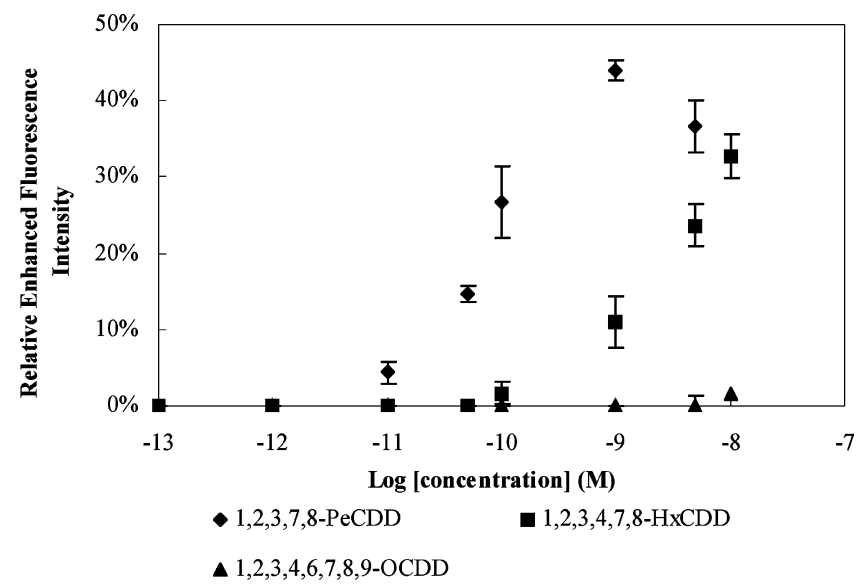

Figure 5. HAHs concentrations vs relative enhanced fluorescence intensity.

Table 5. Estimation of TEQ Values of the Mixtures of Dioxins

\begin{tabular}{cccccc} 
& \multicolumn{3}{c}{ components, pM } & predicted & detected TEQ, \\
\cline { 2 - 4 } sample & TCDD & PeCDD & HxCDD & TEQ, pM & pM (av \pm SD) \\
1 & 50 & 50 & 50 & 82.5 & $83.3 \pm 4.8$ \\
2 & 25 & 25 & 25 & 41.3 & $39.1 \pm 5.7$ \\
3 & 5 & 5 & 5 & 8.3 & $7.9 \pm 1.5$ \\
\hline
\end{tabular}

quantified by this method. To evaluate the solvent effect, toluene and 1,2-dichloroethane was also used to redissolve dioxins in the fly ash extract. The determined TEQ values were $66.9 \pm 7.3 \mathrm{pM}$ in DMSO, $62.8 \pm 6.5 \mathrm{pM}$ in toluene, and $57.2 \pm 10.9 \mathrm{pM}$ in 1,2 dichloroethane, which were lower than the given value $(89.4 \mathrm{pM})$ by HRGC/MS. The shifts are acceptable in the measurement of dioxins. The samples for recovery tests were prepared by adding

(53) Safe, S. H. Crit. Rev. Toxicol. 1994, 24, 87-149. 
Table 6. Results of the Determination of the Samples and the Recoveries

\begin{tabular}{ccccc} 
sample & $\begin{array}{c}\text { initial } \\
\text { TEQ, } \\
\mathrm{pM}\end{array}$ & $\begin{array}{c}\text { added } \\
\text { TCDD, } \\
\mathrm{pM}\end{array}$ & $\begin{array}{c}\text { dertermined } \\
\text { TEQ, pM } \\
(\mathrm{av} \pm \mathrm{SD})\end{array}$ & $\begin{array}{c}\text { recovery, \% } \\
\text { (av } \pm \text { SD) }\end{array}$ \\
1 & 6.69 & 80 & $75.74 \pm 5.6$ & $87.4 \pm 6.5$ \\
2 & 6.69 & 40 & $40.22 \pm 3.4$ & $86.1 \pm 7.3$ \\
3 & 6.69 & 4 & $11.21 \pm 1.3$ & $104.8 \pm 12.2$ \\
\hline
\end{tabular}

the standard solutions of TCDD into the fly ash extract diluted in DMSO. The average recovery was $\sim 93 \%$ (Table 6 ).

\section{CONCLUSIONS}

This study demonstrated a new protocol for a cell-free bioassay based on the AhR mechanism and fluorescence enhancement principle for rapid and sensitive detection of TCDD. The proposed method in this study has several further advantages. First, the operation time is short, $\sim 4 \mathrm{~h}$ ignoring preparation of the rat hepatic cytosol. The cytosol needs 1 or $2 \mathrm{~h}$ more to prepare but can be largely produced as a stock reagent (at $-80^{\circ} \mathrm{C}$ ) for long time use. Second, the operation is simple; no additional reagents or expensive equipment is required. Third, the cell-free protocol can avoid cell culture, and high sensitivity at the femtogram level with a detection limit of $1 \mathrm{pM}(\sim 6 \mathrm{fg}$ /assay) can be achieved, which is competitive with the existing bioassay methods for dioxins.

Although in vitro DRE binding assay may not accurately reflect the toxicity of dioxins to living cells, the non-cell-based bioassays (including the proposed method in this study) can provide valuable information of dioxin contamination. Considering high sensitivity, ease of operation, time saving, and low cost, this protocol is believed to be a promising alternative for detection of dioxins, though the real application of it remains to be intensively and extensively investigated using environmental samples.

\section{ACKNOWLEDGMENT}

This project was supported by the National Science Foundation (No. 30500121) and the Ministry of Science and Technology of the People's Republic of China.

Note Added after ASAP Publication. This paper was posted $9 / 01 / 06$. Minor errors in an e-mail address, Table 1 , and the Acknowledgments were corrected. The paper was reposted on 9/14/06.

Received for review March 10, 2006. Accepted July 27, 2006.

AC060442E 